\title{
A tick cell line as a powerful tool to screen the antimicrobial susceptibility of the tick-borne pathogen Anaplasma marginale
}

\author{
Beatriz Iglesias Alonso \\ Universidade de Sao Paulo \\ Elisa Silva Ventura \\ Universidade de São Paulo \\ Eliane Esteves \\ Universidade de Sao Paulo \\ Maria F.B.M. Galletti \\ Universidade de Sao Paulo \\ Bruno Dall'Agnol \\ IPVDF \\ João Ricardo Martins \\ IPVDF \\ Guilherme Klafke \\ IPVDF \\ José Reck \\ IPVDF

\section{Andrea Cristina Fogaça} \\ Universidade de São Paulo \\ Sirlei Daffre ( $\boldsymbol{\sim}$ sidaffre@icb.usp.br) \\ Universidade de Sao Paulo
}

\section{Research article}

Keywords: Anaplasma, antimicrobial, resistance, drug screening, cell line, tick

Posted Date: May 14th, 2019

DOI: https://doi.org/10.21203/rs.2.9604/v1

License: (c) (i) This work is licensed under a Creative Commons Attribution 4.0 International License.

Read Full License 
Version of Record: A version of this preprint was published at Experimental Parasitology on October 1st, 2020. See the published version at https://doi.org/10.1016/j.exppara.2020.107958. 


\section{Abstract}

Background Anaplasma marginale is the causative agent of the severe bovine anaplasmosis. The tick Rhipicephalus microplus is one of the main vectors of A. marginale in tropical and subtropical regions of world. After the tick bite, the bacterium invades and proliferates within the bovine erythrocytes, causing anemia and impairing milk production and weight gain. In addition, infection can cause abortion and high mortality in areas of enzootic instability. The immunization with live and inactivated vaccines are employed to the control acute bovine anaplasmosis. However, they do not prevent persistent infection. Therefore, infected animals, even if immunized, are reservoirs of the bacterium and contribute to the dissemination of the disease. Antimicrobials are also largely employed for the prophylaxis of bovine anaplasmosis. However, they are often used in subtlethal doses, what can select pre-existing resistant bacteria and induce genetic or phenotypic variations. Therefore, the standardization of an in vitro assay to evaluate the susceptibility of A. marginale strains to different antimicrobials is important to allow the prescription of the more effective treatment, preventing both the selection and spread of resistant strains. Results Initially the antimicrobial susceptibility of two field isolates of A. marginale (Jaboticabal and Palmeira) infecting bovines was evaluated. The least susceptible strain (Jaboticabal) was used for the standardization of an antimicrobial assay using a culture of Ixodes scapularis-derived tick cell line, ISE6. Results showed that enrofloxacin (ENRO) at $0.25,1$ or $4 \mu \mathrm{g} / \mathrm{mL}$ and oxytetracycline (OTC) at 4 or 16 $\mu \mathrm{g} / \mathrm{mL}$ are the most efficient treatments, followed by OTC at $1 \mu \mathrm{g} / \mathrm{mL}$ and imidocarb dipropionate (IMD) at 1 or $4 \mu \mathrm{g} / \mathrm{mL}$. Conclusion In the current study, we present a new in vitro assay using a tick cell line to evaluate the susceptibility of A. marginale to antimicrobials. The maintenance of such culture is much easier than the maintenance of bovine erythrocyte culture, which depends on continuous cell replacement. This assay may be used to guide cattle farmers to the correct use of antimicrobials. The choice of the most suitable antimicrobial is essential to eliminate persistent infections, preventing the spread of resistant strains and helping in the control of bovine anaplasmosis.

\section{Background}

Anaplasma marginale (Rickettsiales, Anaplasmataceae) is a tick-borne obligate intracellular ß-Gramnegative proteobacterium that causes the severe bovine anaplasmosis. The bacterial invasion and proliferation within the bovine erythrocytes causes cell destruction and consequently anemia, impairing also milk production and weight gain. In addition, infection can cause abortion and high mortality level in areas of enzootic instability ( 1 ). Bovine anaplasmosis is widely distributed throughout the world, with cases reported in the Americas, Europe, Asia, Africa and Australia ( 2,3$)$. In those areas, more than 20 species of ticks have already been implicated as biological vectors of $A$. marginale $(1,2)$.

In tropical and subtropical regions, Rhipicephalus microplus (formerly named Boophilus microplus) and Rhipicepahuls annulatus are incriminated as the main vectors ( 4 ). The transmission of $A$. marginale by R. microplus can be both intrastadial and transstadial ( 5 ), while the transovarial transmission is still controversial ( 6 ). In addition, males seem to play an important role as vectors, as they perform multiple blood meals, even in more than one host, and also exhibit greater mobility and longevity compared to 
females $(7,8)$. Transmission may also occur mechanically through either the bite of hematophagous insects (flies, mosquitoes, tabanids), which carry residues of contaminated blood on their mouthparts, or fomites, such as needles and gloves ( 2 ).

Immunization with live and inactivated vaccines has been used to control bovine anaplasmosis. However, despite both types of vaccines induce protective immunity that reduces and prevents the clinical disease, they do not prevent persistent infection. Therefore, even if immunized, infected animals are reservoirs of the bacterium and contribute to the dissemination of the disease (9). In Brazil, as in other countries, a strain of $A$. marginale subspecies centrale has been used as vaccine, conferring cross-immunity against A. marginale $(9,10)$. Nonetheless, there are significant differences in the efficacy of this vaccine depending on the region and the isolate of the bacterium. In addition, immunization with alive $A$. marginale subsp. centrale causes an infection that can lead to adverse clinical reactions $(11,12)$.

In addition to vaccines, antimicrobials are largely employed for the chemoprophylaxis of bovine anaplasmosis. In endemic areas in the USA, the addition of chlortetracycline to the animals' food is frequent. On the other hand, in Brazil, where the administration of antimicrobials within the animals' diet is rare, the use of subtherapeutic dosage of injectable antimicrobials, such as imidocarb dipropionate (IMD) and oxytetracycline (OTC), has become a common practice for the prevention of anaplasmosis ( 13-15). Currently, the drug of choice for the treatment of bovine anaplasmosis is OTC, but other drugs may be employed, such as IMD and enrofloxacin (ENRO) ( 16 ).

Antimicrobials used in subtlethal doses can frequently select pre-existing resistant bacteria and induce genetic or phenotypic variations. In addition, antimicrobials can act as signaling molecules, for instance, activating virulence genes $(17,18)$. Two multidrug resistance pumps were identified in the genome of $A$. marginale (19). Although the clinical significance of these genes has yet to be elucidated and, to date, there are no reports on $A$. marginale antimicrobial resistance, the misuse of antimicrobials may favor the selection of resistant strains. Indeed, conflicting data on the success of antimicrobial therapies in endemic areas of bovine anaplasmosis suggest that distinct isolates of $A$. marginale exhibit differences in antimicrobial susceptibility $(16,20)$. Therefore, the standardization of in vitro assays to assess the susceptibility of $A$. marginale strains to different antimicrobials is important to allow the prescription of the most effective treatment, preventing the spread of resistant strains and helping in the control of bovine anaplasmosis.

In the current study, we present the evaluation of the antimicrobial susceptibility of two field isolates of $A$. marginale (Jaboticabal and Palmeira) infecting bovines. The least susceptible strain (Jaboticabal) was used for the standardization of an antimicrobial assay using a culture of I. scapularis-derived tick cell line, ISE6. Results showed that the in vitro assay using tick cells is a practical and powerful tool to evaluate the susceptibility of $A$. marginale to antimicrobials.

\section{Results}




\section{Treatment of $\boldsymbol{A}$. marginale infection in cattle}

Considering the previously reported data on the differences in the susceptibility of different $A$. marginale isolates to antimicrobials $(16,20)$, we evaluated the efficacy of the treatment with OTC or IMD in bovines experimentally infected with two different field strains of $A$. marginale (Jaboticabal and Palmeira). The monitoring of parasitemia was performed daily from the first to the $54^{\text {th }}$ day postinfection through the blood smear test and the treatment regimen followed the criteria described in Methods. Although a small delay in parasitemia detection was observed after inoculation with the Jaboticabal strain ( 21 and 23 days) in relation to the Palmeira strain (19 and 23 days), all animals became infected, reaching parasitemia levels up to $3.7 \%$ (Table 1; Fig. 1). In addition, all infected animals exhibited clinical signals characteristic for anaplasmosis, such as anemia and fever. Indeed, the PCV of calves ranged from $32 \%$ (pre-infection) to $14 \%$ (post-infection) and the RT ranged from $38.3^{\circ} \mathrm{C}$ (preinfection) to $41.2^{\circ} \mathrm{C}$ (post-infection). Nonetheless, there were no significant differences between PCV and RT mean values obtained from animals infected with either Jaboticabal or Palmeira strains. The animals infected with the Palmeira strain required the treatment with only two doses of OTC to be cured (reduction of the parasitemia to zero; $\mathrm{P} 1=33$ days; $\mathrm{P} 2=30$ days), while the animals infected with the Jaboticabal strain needed four doses of this antimicrobial ( $\mathrm{J} 1=47$ days; $\mathrm{J} 2=51$ days) (Table 1 , Fig. 1 ). In relation to IMD treatment, the animals infected with the Jaboticabal strain were cured with two (J3 $=44$ days) or three (J4 = 52 days) doses (Table 1, Fig. 1). On the other hand, the animals infected with Palmeira strain needed only a single dose to be cured (P3 and P4 = 29 days); (Table 1, Fig. 1). Together, the results show that the Jaboticabal strain is less susceptible to both antimicrobials than the Palmeira strain.

\section{Establishment of an in vitro assay for the screening of $A$. marginale susceptibility to antimicrobials}

The Jaboticabal strain of $A$. marginale, which was less susceptible to the treatment with antimicrobials in vivo, was selected to establish an in vitro antimicrobial assay. To that end, we first evaluated the susceptibility of the embryonic cells of the tick I. scapularis (ISE6) to this strain of $A$. marginale. Characteristic vacuoles filled with $A$. marginale were observed within ISE6 cells seven days post-infection (Fig. 2). ISE6 cells were then treated with ENRO $(4 \mu \mathrm{g} / \mathrm{mL})$, IMD $(1 \mu \mathrm{g} / \mathrm{mL})$, or OTC $(16 \mu \mathrm{g} / \mathrm{mL})$, concentrations previously reported to efficiently kill $A$. marginale inside bovine erythrocytes in vitro ( 20 ). After $24 \mathrm{~h}$, cells were infected and the bacterial growth was evaluated on days $1^{\text {st }}, 3^{\text {th }}, 5^{\text {th }}$, and $7^{\text {th }}$ postinfection (Fig. 3). Seven days post-infection the load of $A$. marginale within ISE6 cells treated with either ENRO or OTC was approximately two orders of magnitude lower than the control group (free antimicrobial; FA). In fact, significant differences between the control group and either ENRO or OTC groups were observed since the fifth day post-infection. On the other hand, we did not detect any significant differences in bacterial growth in cells treated with ENRO and OTC (Fig. 3). In addition, there was a slight but significant reduction in bacterial load in the group treated with IMD compared to the control group after 5 and 7 days post-infection. 
We then analyzed the bacterial growth under lower concentrations of ENRO $(0.25 \mu \mathrm{g} / \mathrm{mL}, 1 \mu \mathrm{g} / \mathrm{mL})$ and OTC $(1 \mu \mathrm{g} / \mathrm{mL}, 4 \mu \mathrm{g} / \mathrm{mL})$ than those used in the first experiment. As reference, the same concentrations used in the first experiment were employed (ENRO; $4 \mu \mathrm{g} / \mathrm{mL}$ and OTC; $16 \mu \mathrm{g} / \mathrm{mL}$ ). In addition, a higher (4 $\mu \mathrm{g} / \mathrm{mL})$ and a lower $(0.25 \mu \mathrm{g} / \mathrm{mL})$ concentrations of IMD than the previously tested $(1 \mu \mathrm{g} / \mathrm{mL})$ were also evaluated. ENRO effectively reduced bacterial growth at all concentrations, with a bacterial load of approximately two orders of magnitude lower than the control (Fig. 4). The same effect was observed for the concentrations of $4 \mu \mathrm{g} / \mathrm{mL}$ and $16 \mu \mathrm{g} / \mathrm{mL}$ of OTC, while a minor but still significant activity was detected with $1 \mu \mathrm{g} / \mathrm{mL}$. A slight but significant reduction of the bacterial load was detected with IMD at 4 $\mu \mathrm{g} / \mathrm{mL}$ and $1 \mu \mathrm{g} / \mathrm{mL}$. Conversely, we did not detect a significant difference between the IMD treatment at $0.25 \mu \mathrm{g} / \mathrm{mL}$ and the control group. In summary, the in vitro assays revealed that the Jaboticabal strain of A. marginale is more susceptible to ENRO and OTC than to IMD.

\section{Discussion}

Antimicrobials, such as OTC, IMD, and ENRO, are widely used for bovine anaplasmosis prophylaxis and chemotherapy ( 16 ). In Brazil, alarming data from the Department of Agriculture of Rio Grande do Sul State (SEAPI) show that these antimicrobials are among the most commonly used veterinary drugs on farms, only behind acaricides (SEAPI, unpublished results). The indiscriminate administration of antimicrobials, frequently in sublethal concentrations, to humans and livestock can promote antimicrobial resistance $(17,18)$. It is known that a substantial percentage of an administrated antimicrobial (up to $80 \%$ depending on the antimicrobial) is excreted to the environment in its active form, where it can continue exerting its effects ( 18 ). Contradictory results were previously reported on the success of antimicrobial therapies, suggesting that different isolates of $A$. marginale exhibit distinct antimicrobial susceptibility $(16,20)$. Therefore, we analyzed the antimicrobial susceptibility of two field strains of $A$. marginale (Jaboticabal and Palmeira) infecting bovines. The Palmeira strain was isolated from a region in which there was a massive use of heterologous $A$. marginale subsp. centrale live vaccine. On the other hand, Jaboticabal strain was originally isolated from a region in which this vaccine was rarely used, particularly because there are recurrent complaints about vaccine efficacy. The cure of the animals infected with the Palmeira strain was obtained with two applications of OTC (P1 and P2) and one application of IMD (P3 and P4), which is in accordance with the manufacturer's recommendations (Zoetis and MSD Animal Health, Brazil). However, animals infected with the Jaboticabal strain were cured only after four applications of OTC (J1 and J2), and two (J3) or three (J4) of IMD. These results showed that the Jabotical strain exhibits a lower susceptibility to the tested antimicrobials than the Palmeira strain.

The Jaboticabal strain was then selected to the standardization of an in vitro assays to assess the susceptibility of $A$. marginale to different antimicrobials. The use of an in vitro assay to monitor the susceptibility of field strains of $A$. marginale to antimicrobials is essential to direct the correct use of the drug by veterinarian practitioners and cattle farmers, avoiding selection and spread of resistant strains. Assays for the detection of $A$. marginale susceptibility to antimicrobials were proposed by Coetzee et al. (2016) using an assay employing bovine erythrocytes $(16,20)$; however, the maintenance of such 
culture is largely hampered by the need for continuous erythrocyte replacement. Therefore, we established an in vitro assay using the embryonic cell line ISE6 of I. scapularis ( 21 ), which is easy to maintain in laboratory conditions ( 21 ). Indeed, in the last years, tick cell lines have been shown to be a potent tool for the study of parasite biology and parasite-host relationship ( 22 ). These models allow not only a great control of the experimental conditions, but also the evaluation of molecular interactions between ticks and the pathogens transmitted by them without involving the use of vertebrate animals. After in vitro pre-evaluation, in vivo analysis may be performed.

ISE6 cells had been previously reported to be susceptible to the strain Virginia of $A$. marginale( 23 ). In the current study, we showed that this cell line is also susceptible to infection with the Jaboticabal strain of $A$. marginale, exhibiting the characteristic vacuoles filled with $A$. marginale previously detected in the BME26 cell line of $R$. microplus ( 24 ). We then analyzed the effects of different antimicrobials on the growth of the strain Jaboticabal in vitro. The most efficient treatment was ENRO at $0.25,1$ and $4 \mu \mathrm{g} / \mathrm{mL}$ and OTC at 4 and $16 \mu \mathrm{g} / \mathrm{mL}$, followed by OTC at $1 \mu \mathrm{g} / \mathrm{mL}$ and IMD at 1 and $4 \mu \mathrm{g} / \mathrm{mL}$. IMD inhibited bacterial growth in a dose-dependent manner, whereas OTC exhibited a dose-dependent activity only at 1 and $4 \mu \mathrm{g} / \mathrm{mL}$, but not at $16 \mu \mathrm{g} / \mathrm{mL}$. It is possible that a dose-dependent effect would be obtained using lower concentrations of both OTC and ENRO, as these antimicrobials were the most effective against the strain Jaboticabal of $A$. marginale.

Our data differ from the results previously obtained by Coetzee et al. (2006) (20). In the referred study, flow cytometry analyses showed that ENRO and IMD were more effective against the Oklahoma (OK)and Virginia (VGN) strains of $A$. marginale infecting bovine erythrocytes than OTC. The differences between the previously reported ( 20 ) and our data may be due to the different strains, host cell lines and methodology employed in each study.

\section{Conclusions}

In conclusion, our results demonstrate that different strains of $A$. marginale infecting calves exhibit distinct susceptibility to antimicrobials. In addition, we present a new in vitro assay with tick cells to screen the susceptibility of $A$. marginale to antimicrobials. This assay may guide veterinarians and cattle farmers to choose of the most effective(s) antimicrobial(s) to treat an Anaplasmosis, leading to the elimination of persistent infections and preventing the spread of resistant strains. Furthermore, the standardized trial with a tick cells culture will add a new front of analysis to evaluate the efficacy of novel antimicrobial drugs and will also help monitoring $A$. marginale isolates suspicious to be resistant to antimicrobials.

\section{Methods}

\section{Anaplasma marginale}


Two strains of $A$. marginale were used in the experiments: Jaboticabal and Palmeira. The Jaboticabal strain was isolated from bovines in the municipality of Jaboticabal, São Paulo state, southeast Brazil $\left(21^{\circ} 15^{\prime} 18^{\prime \prime} \mathrm{S} ; 48^{\circ} 19^{\prime} 20^{\prime \prime} \mathrm{W}\right)(25)$. The strain Palmeira was isolated in the beginning of 2,000's from Holstein dairy bovines showing clinical anaplasmosis in the municipality of Palmeira das Missões, Rio Grande do Sul state, southern Brazil (27 $54^{\prime} 09^{\prime \prime}$ S; $53^{\circ} 18^{\prime} 26^{\prime \prime}$ W). After isolation, both strains were cryopreserved in liquid nitrogen.

\section{Calves and tick cell line ISE6}

Eight male calves (Bos taurus taurus) of the Aberdeen-Angus breed were acquired from the tick-free area in Santa Vitória do Palmar municipality, Rio Grande do Sul State, Brazil. All of them were seronegative to A. marginale in ELISA assays (data not shown). All calves, aging from 10 to 14 months and weighting between 140 and $220 \mathrm{~kg}$, were kept in individual screened stalls. During the experiments, animals were fed thrice a day with alfafa hay and pelleted food for cattle, and had free access to water. At the end of the experiment the animals were discarded according to the procedure approved by the protocol stated in the section "Ethics approval and consent to participate". The embryonic cell line ISE6, derived from I. scapularis (21), was cultured as previously described ( 26 ). Cell growth and viability were assessed by cell counting in a Neubauer chamber using optical microscopy after trypan blue staining.

\section{Calf experimental infection and antimicrobial treatment}

Calves were experimentally infected by intravenous (jugular vein) inoculation of approximately $10^{6}$ bovine erythrocytes parasitized by $A$. marginale strain Jaboticabal (animals $\mathrm{J} 1, \mathrm{~J} 2, \mathrm{~J} 3$, and $\mathrm{J} 4$ ) or strain Palmeira (animals P1, P2, P3, and P4). The parasitemia was monitored daily. To that end, peripheral blood smear was stained with the Instant-Prov kit for hematological analyses (NewProv Produtos para Laboratório, Pinhais, PR, Brazil). Then, the number of infected erythrocytes in 10 different microscopic fields was determined and used to calculate the parasitemia (\% of infected erythrocytes). In addition, the rectal temperature (RT) and the packed cell volume (PCV) were also daily evaluated. The treatment protocol was based on guidelines of Brazilian Ministry of Agriculture for antimicrobial efficacy test for new drugs. After the calves reached a parasitemia $>2 \%$, treatment with injectable antimicrobials was started, using either OTC (Terramicina, Zoetis, Brazil - 20 mg / kg) (J1, J2, P1, and P2) or IMD (Imizol, MSD Animal Health, Brazil - $30 \mathrm{mg} / \mathrm{kg})(\mathrm{J} 3, \mathrm{J4}, \mathrm{P} 3$, and P4). Another treatment with the same dose of OTC was repeated if the animal presented parasitemia $1 \%$ three days after the treatment onset. In the case of IMD, the same treatment was repeated if parasitemia was $1 \%$ seven days after the administration of the first dose. The animal was considered cured when the parasitemia was zero for at least three consecutive days.

\section{ISE6 cells infection and antimicrobial treatment}


The antimicrobials OTC (Sigma-Aldrich, Israel, final concentrations of $1 \mu \mathrm{g} / \mathrm{mL}, 4 \mu \mathrm{g} / \mathrm{mL}$ or $16 \mu \mathrm{g} / \mathrm{mL}$ ), ENRO (Floxiclin, Biofarm Química e Farmacêutica, Brazil; final concentrations of $0.25 \mu \mathrm{g} / \mathrm{mL}, 1 \mu \mathrm{g} / \mathrm{mL}$ or $4 \mu \mathrm{g} / \mathrm{mL}$ ) or IMD (Imicarb Eurofarma Laboratories S.A., Brazil; final concentrations of $0.25 \mu \mathrm{g} / \mathrm{mL}, 1$

$\mu \mathrm{g} / \mathrm{mL}$ or $4 \mu \mathrm{g} / \mathrm{mL}$ ) were added to ISE6 cells $\left(1.510^{6}\right)$ in L15B infection medium ( 27 ). After $24 \mathrm{~h}$ at $34^{\circ} \mathrm{C}$, cells were challenged with $A$. marginale strain Jaboticabal. To that end, infected bovine blood was defrosted in a water-bath at $37^{\circ} \mathrm{C}$, centrifuged at $5000 \mathrm{~g}$ for $10 \mathrm{~min}$ at $4^{\circ} \mathrm{C}$ and the resulting pellet was washed twice in sterile phosphate-buffered saline (PBS). The final pellet, containing bacteria and cellular debris, was suspended in L15B infection medium ( 27 ) and used as inoculum at a multiplicity of infection (MOI) of 100. After incubation at $34^{\circ} \mathrm{C}$ from 1 up to 7 days, the supernatant was discarded, the cell monolayer was washed with PBS and detached with a Trypsin-EDTA solution (Vitrocell, Brazil). The cell suspension was centrifuged at $3000 \times \mathrm{g}$ for $10 \mathrm{~min}$ at $4^{\circ} \mathrm{C}$. The genomic DNA (gDNA) was extracted from resulting pellet and used for bacterial quantification. Five biological replicates were processed for each group.

\section{Quantification of $\boldsymbol{A}$. marginale by real-time quantitative PCR}

Total gDNA was extracted from ISE6 cells using Kit Invisorb Spin Tissue Mini Kit (STRATEC Molecular, Germany) according to the manufacturer's instructions. The number of $A$. marginale in ISE6 cells was determined by quantitative real-time PCR (qPCR) using specific primers and a hydrolysis probe for $m s p 5$, the encoding gene of the major surface protein 5 of $A$. marginale ( 28 ). Briefly, the amplification reactions were performed in a final volume of $15 \mu \mathrm{l}$ containing $2 \mu \mathrm{l}$ of gDNA (approximately $100 \mathrm{ng}$ ), $2 \mu \mathrm{l}$ of a mixture of forward and reverse primers $(0.6 \mu \mathrm{M}$ each), $0.02 \mu$ of TaqMan probe, $7.5 \mu$ l of Maxima Probe/ROX qPCR Master Mix (Thermo Fisher Scientific), and $3.5 \mu \mathrm{l}$ of ultrapure water. The reactions were performed on a StepOnePlusTM Real-Time PCR System (Thermo Fisher Scientific) using the following thermocycler program: $10 \mathrm{~min}$ at $95^{\circ} \mathrm{C}$, followed by 40 cycles of $15 \mathrm{~s}$ at $95^{\circ} \mathrm{C}, 30 \mathrm{~s}$ at $60^{\circ} \mathrm{C}$, and $45 \mathrm{~s}$ at $72{ }^{\circ} \mathrm{C}$. The cycle of quantification $(\mathrm{Cq})$ values of reactions using a dilution series of $10^{2}$ to $10^{7}$ copies of $m s p 5$ cloned into a plasmid (pGEM-®T Easy, Promega, USA) were used to establish a standard curve for determining the absolute number of $A$. marginale in each sample. All samples were analyzed in three technical replicates.

\section{Light microscopy}

Seven days post-infection, ISE6 cells were collected by scraping and centrifuged onto microscope slides through five pulses of 10 seconds at $100 \mathrm{rpm}$ each using a Citospin Brand (Fanem, Brazil). Cells were airdried and stained with Panoptico (Newprov). The images were acquired in an inverted microscope (Zeiss Primovert, Gottingen, Germany) under Plan-NeoFluar 100x/1.30 oil objective, coupled to a digital camera system (Axiocam 105 color, Zeiss) and processed by the Zeiss Software (ZENcore).

\section{Statistical analysis}


The statistical significance of the differences in the bacteria number between the experimental and control groups was evaluated using GraphPad Prism version 7.0 for Windows (GraphPad Software, San Diego, CA, USA). The Kruskal-Wallis test was used to assess similarities between the groups, and the Mann-Whitney test was used to compare the medians. A $p$-value of less than $0.05(P<0.05)$ was considered statistically significant.

\section{List The Abbreviations}

ENRO: enrofloxacin, ELISA: enzyme-linked immunosorbent assay, IMD: imidocarb dipropionate, MOI: Multiplicity of infection, OTC: oxytetracycline, PBS: phosphate-buffered saline, PCV: packed cell volume, RT: rectal temperature.

\section{Declarations}

\section{Ethics approval and consent to participate}

All experimental procedures involving animals were carried out in accordance with the Brazilian National Law number 11,794 and approved by the animal ethics committee of the Instituto de Pesquisas Veterinárias Desidério Finamor (IPVDF), Rio Grande do Sul, Brazil (protocol number 024/2012). Written consent to use the animals in this study from the breeder of the animals.

\section{Consent to publish}

Not applicable

\section{Availability of data and material}

Not applicable

\section{Competing interests}

The authors declare that the research was conducted in the absence of any commercial or financial relationships that could be construed as a potential conflict of interest.

\section{Funding}

This work was supported by funds from the São Paulo Research Foundation (FAPESP; 2013/26450-2), the Rio Grande do Sul Research Foundation (FAPERGS), the National Council for Scientific and Technological Development [CNPq; grants CNPq 304382/2017-5; The National Institutes of Science and 
Technology Program in Molecular Entomology (INCT-EM)], the Coordination for the Improvement of Higher Education Personnel (CAPES), BIA, ESV, and MFBMG were supported by fellowships from FAPESP. The funding agencies did not play a role in the study design, data collection, analysis, interpretation or writing of the manuscript.

\section{Author's contributions}

BIA, ESV, MFBMG and BDA generated biological samples and performed the experiments; JRM, GK, JR, $A C F$, and SD: designed the experiments and analyzed data; JRM, GK, JR, ACF, and SD: contributed reagents, materials, and analysis tools; EE, JR, ACF and SD: wrote the paper. All authors read and approved the final manuscript.

\section{Acknowledgements}

We would like to thank Mauro Javier Cortez Veliz for technical assistance in light microscopy, Ugo Araújo Souza for his help in experiments with cattle, and Carlos Alexandre Ferreira for his valuable suggestions.

\section{References}

1. Kocan KM, de la Fuente J, Blouin EF, Garcia-Garcia JC. Anaplasma marginale (Rickettsiales: Anaplasmataceae): recent advances in defining host-pathogen adaptations of a tick-borne rickettsia. Parasitology 2004;129 Suppl:S285-300.

2. Aubry P, Geale DW. A review of bovine anaplasmosis. Transbound Emerg Dis 2011;58(1):1-30.

3. Kocan KM, de la Fuente J, Blouin EF, Coetzee JF, Ewing SA. The natural history of Anaplasma marginale. Vet Parasitol 2010;167(2-4):95-107.

4. Kocan KM, de la Fuente J, Blouin EF. Advances toward understanding the molecular biology of the Anaplasma-tick interface. Front Biosci 2008;13:7032-45.

5. Aguirre DH, Gaido AB, Vinabal AE, De Echaide ST, Guglielmone AA. Transmission of Anaplasma marginale with adult Boophilus microplus ticks fed as nymphs on calves with different levels of rickettsaemia. Parasite 1994;1(4):405-7.

6. Esteves E, Pohl PC, Klafke GM, Reck J, Fogaca AC, Martins JR, et al. Low temperature affects cattle tick reproduction but does not lead to transovarial transmission of Anaplasma marginale. Vet Parasitol 2015;214(3-4):322-6.

7. Kocan KM. Development of Anaplasma marginale Theiler in Ixodid ticks: coordinated development of rickettsial organism and its tick host. In: Sauer JR, Hair JA, editors. Morphology, physiology, and behavioral biology of ticks. New York, N.Y.: John Wiley \& Sons, Inc.; 1986. p. 472-505. 
8. Mason CA, Norval RAI. The transfer of Boophilus microplus (Acarina: Ixodidae) from infested to uninfested cattle under field conditions Vet Parasitol 1981;8(2):185-188.

9. Kocan KM, de la Fuente J, Guglielmone AA, Melendez RD. Antigens and alternatives for control of Anaplasma marginale infection in cattle. Clin Microbiol Rev 2003;16(4):698712.

10. Dalto AGC, Reck J, Martins JR, Bitencourt APG, Feltrin C, Driemeier D. Bovine anaplasmosis control through immunization with Anaplasma centrale. Pesq Vet Bras 2018;38(6):1064-1067.

11. Potgieter FT. Epizootiology and control of anaplasmosis in south africa. J S Afr Vet Assoc 1979;50(4):367-72.

12. Turton JA, Katsande TC, Matingo MB, Jorgensen WK, Ushewokunze-Obatolu U, Dalgliesh RJ. Observations on the use of Anaplasma centrale for immunization of cattle against anaplasmosis in Zimbabwe. Onderstepoort J Vet Res 1998;65(2):81-6.

13. Mathers JJ, Flick SC, Cox LA, Jr. Longer-duration uses of tetracyclines and penicillins in U.S. food-producing animals: Indications and microbiologic effects. Environ Int 2011;37(5):991-1004.

14. Ribeiro MFB. Use of standardized inoculum of Anaplasma marginale and chemoprophylaxis to control bovine anaplasmosis. Arquivo Brasileiro de Medicina Veterinária e Zootecnia 2003;55(1):21-26.

15. Sacco AMS. Controle de surtos de Tristeza Parasitária Bovina. Circular Técnica. Bagé, RS: EMBRAPA Pecuária Sul; 2002.

16. Coetzee JF, Apley MD, Kocan KM. Comparison of the efficacy of enrofloxacin, imidocarb, and oxytetracycline for clearance of persistent Anaplasma marginale infections in cattle. Vet Ther 2006;7(4):347-60.

17. Blazquez J, Couce A, Rodriguez-Beltran J, Rodriguez-Rojas A. Antimicrobials as promoters of genetic variation. Curr Opin Microbiol 2012;15(5):561-9.

18. Andersson DI, Hughes D. Microbiological effects of sublethal levels of antibiotics. Nat Rev Microbiol 2014;12(7):465-78.

19. Brayton KA, Kappmeyer LS, Herndon DR, Dark MJ, Tibbals DL, Palmer GH, et al. Complete genome sequencing of Anaplasma marginale reveals that the surface is skewed to two superfamilies of outer membrane proteins. Proc Natl Acad Sci U S A 2005;102(3):844-9.

20. Coetzee JF, Apley MD, Kocan KM, Jones DE. Flow cytometric evaluation of selected antimicrobial efficacy for clearance of Anaplasma marginale in short-term erythrocyte cultures. J Vet Pharmacol Ther 2006;29(3):173-83.

21. Munderloh UG, Jauron SD, Fingerle V, Leitritz L, Hayes SF, Hautman JM, et al. Invasion and intracellular development of the human granulocytic ehrlichiosis agent in tick cell culture. J Clin Microbiol 1999;37(8):2518-24. 
22. Bell-Sakyi L, Darby A, Baylis M, Makepeace BL. The Tick Cell Biobank: A global resource for in vitro research on ticks, other arthropods and the pathogens they transmit. Ticks Tick Borne Dis 2018;9(5):1364-1371.

23. Zivkovic Z, Blouin EF, Manzano-Roman R, Almazan C, Naranjo V, Massung RF, et al. Anaplasma phagocytophilum and Anaplasma marginale elicit different gene expression responses in cultured tick cells. Comp Funct Genomics 2009:705034.

24. Esteves E, Bastos CV, Zivkovic Z, de La Fuente J, Kocan K, Blouin E, et al. Propagation of a Brazilian isolate of Anaplasma marginale with appendage in a tick cell line (BME26) derived from Rhipicephalus (Boophilus) microplus. Vet Parasitol 2009;161(12):150-3.

25. de Andrade GM, Machado RZ, Vidotto MC, Vidotto O. Immunization of bovines using a DNA vaccine (pcDNA3.1/MSP1b) prepared from the Jaboticabal strain of Anaplasma marginale. Ann N Y Acad Sci 2004;1026:257-66.

26. Esteves E, Lara FA, Lorenzini DM, Costa GH, Fukuzawa AH, Pressinotti LN, et al. Cellular and molecular characterization of an embryonic cell line (BME26) from the tick Rhipicephalus (Boophilus) microplus. Insect Biochem Mol Biol 2008;38(5):568-80.

27. Munderloh UG, Blouin EF, Kocan KM, Ge NL, Edwards WL, Kurtti TJ. Establishment of the tick (Acari:Ixodidae)-borne cattle pathogen Anaplasma marginale (Rickettsiales:Anaplasmataceae) in tick cell culture. J Med Entomol 1996;33(4):656-64. 28. Bifano TD, Ueti MW, Esteves E, Reif KE, Braz GR, Scoles GA, et al. Knockdown of the Rhipicephalus microplus cytochrome c oxidase subunit III gene is associated with a failure of Anaplasma marginale transmission. PLoS One 2014;9(5):e98614.

\section{Table}

Table 1 could not be inserted here due to technical difficulties. It has been attached as an excel file in the Supplementary files.

\section{Figures}



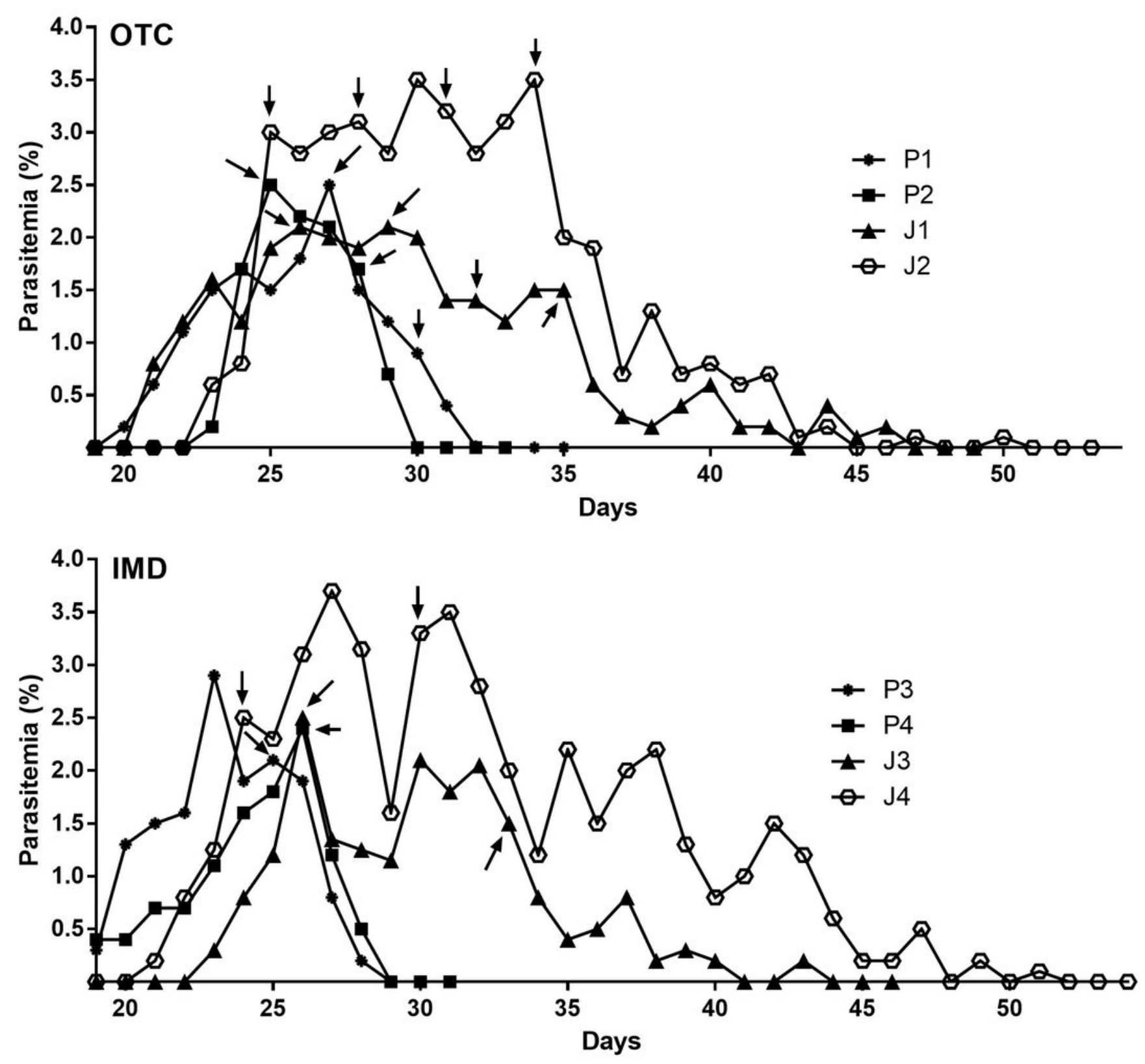

Figure 1

Parasitemia in calves experimentally infected with A. marginale and treated with OTC or IMD. Calves were infected with 106 bovine erythrocytes parasitized by either the strain Jaboticabal (J1, J2, J3, and J4) or Palmeira (P1, P2, P3, and P4) of A. marginale. The determination of the parasitemia was monitored daily through the blood smear stained with the Instant-Prov kit. The treatment was done with either OTC (20 $\mathrm{mg} / \mathrm{kg})(\mathrm{J} 1, \mathrm{~J} 2, \mathrm{P} 1$, and P2) or IMD (30 mg/kg) (J3, J4, P3, and P4). The antimicrobial treatment was initiated when the animal presented a parasitemia greater than $2 \%$ and repeated following the criteria described in Methods. Arrows indicate the days of the antimicrobial administration. 


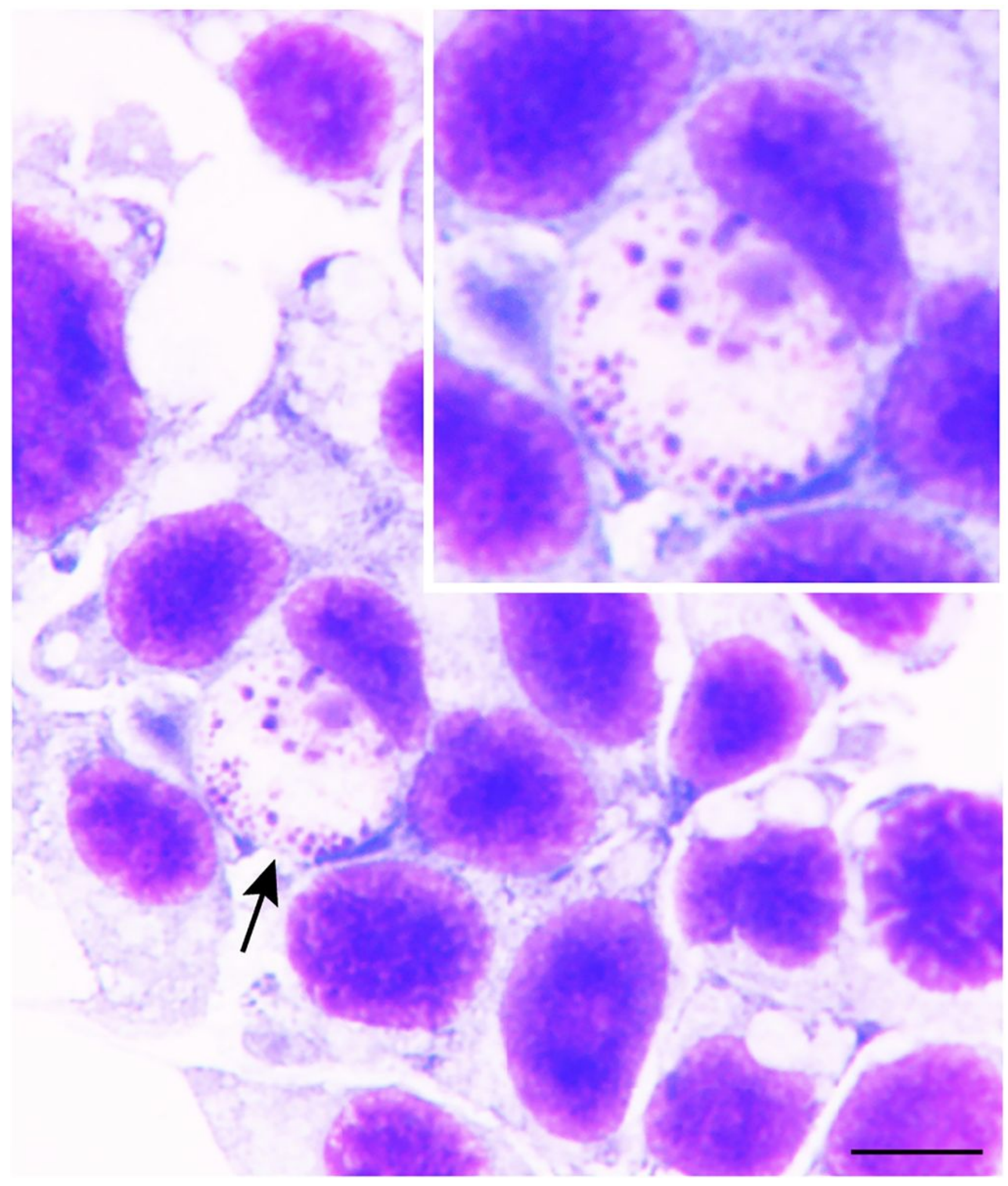

Figure 2

Light microscopy of ISE6 cells infected with the strain Jaboticabal of A. marginale. Seven days postinfection, cells were stained with Panoptico. Arrow indicates vacuole filled with A. marginale. The nuclei are stained in purple pink. Scale bar $=5 \mu \mathrm{m}$. 


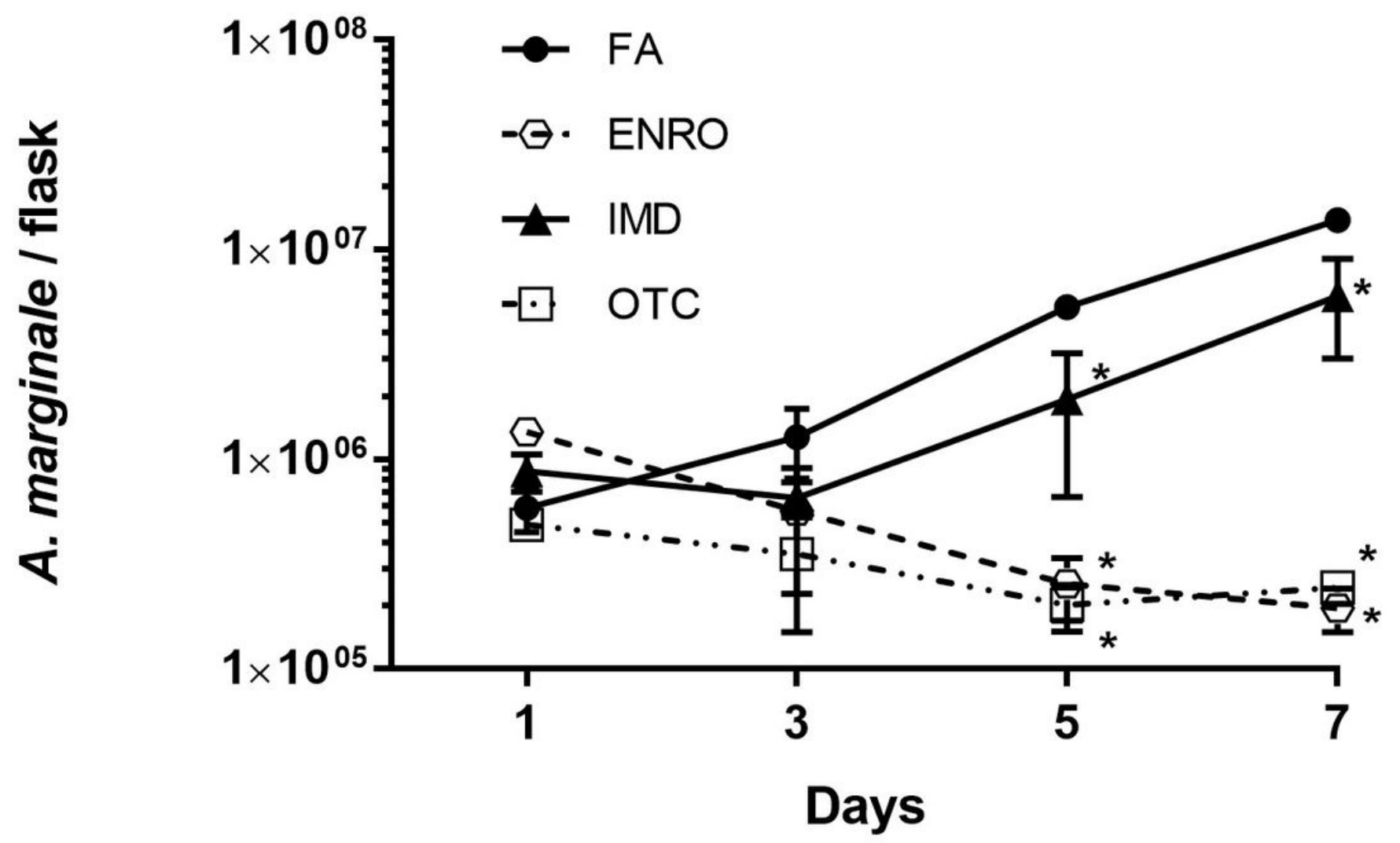

Figure 3

Temporal analysis of A. marginale growth in the presence or absence of antimicrobials. The antimicrobials ENRO $(4 \mu \mathrm{g} / \mathrm{mL})$, IMD $(1 \mu \mathrm{g} / \mathrm{mL})$ or OTC $(16 \mu \mathrm{g} / \mathrm{mL})$ were added to ISE6 cells and, after 24 $h$, cells were infected with the strain Jaboticabal of A. marginale $(\mathrm{MOI}=100)$. As control, cells were incubated in the absence of antimicrobials (FA: free antimicrobial). After 1, 3, 5 and 7 days post-infection, the cells were collected, the gDNA was extracted and used as template for the bacterial quantification by qPCR. The data represent a median of 5 biological replicates \pm standard deviation. The bacterial load for each treatment at each time point post-infection was compared by Kruskal-Wallis followed by MannWhitney. Asterisks indicate significant differences $(P<0.05)$. 


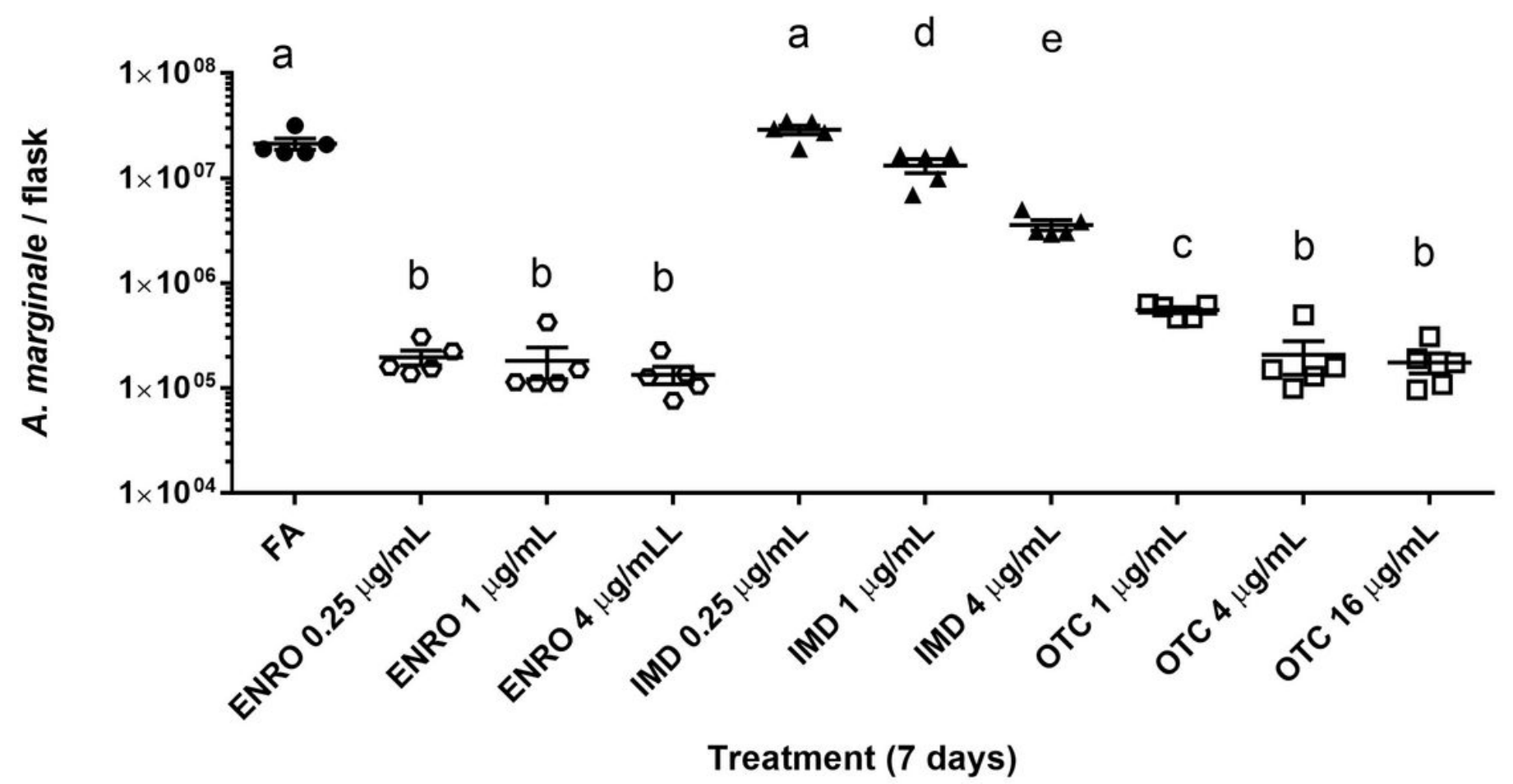

Figure 4

Susceptibility of A. marginale to different concentration of antimicrobials. ISE6 cells were incubated for $24 \mathrm{~h}$ with $\operatorname{ENRO}(0.25,1$, or $4 \mu \mathrm{g} / \mathrm{mL})$, IMD $(0.25,1$, or $4 \mu \mathrm{g} / \mathrm{mL})$ or OTC $(1,4$, or $16 \mu \mathrm{g} / \mathrm{mL})$ and then infected with $\mathrm{A}$. marginale $(\mathrm{MOI}=100)$. As control, cells were incubated in the absence of antimicrobials (FA: free antimicrobial). After 7 days, the cells were collected, the gDNA was extracted and used as template for the bacterial quantification by qPCR. The data represent a median of 5 biological replicates \pm standard deviation. The bacterial load for each treatment at each time point post-infection was compared by Kruskal-Wallis followed by Mann-Whitney. The different letters represent data with significant differences $(P<0.05)$.

\section{Supplementary Files}

This is a list of supplementary files associated with this preprint. Click to download.

- NC3RsARRIVEGuidelinesChecklistAlonsoetalBMCMicrobiol.pdf

- Table1.xlsx 